\title{
Anatomie einer Seele
}

Collagen/Text: Jupe Haegler, Verdichtungen:

Jacqueline Crevoisier

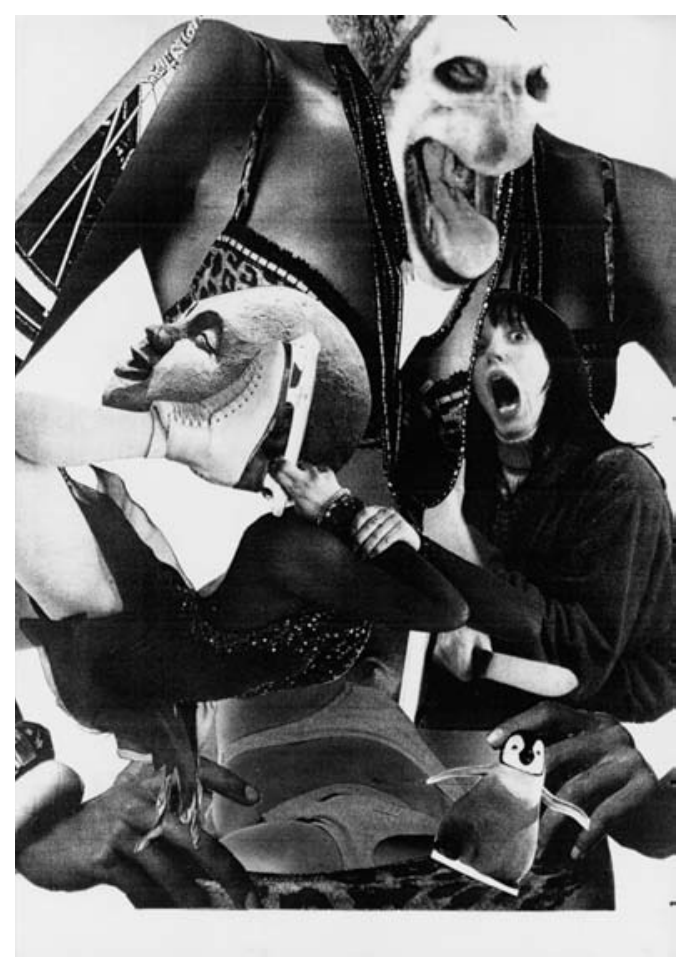

Ohne Entwurf und Plan suche ich in meiner Zeitungsausschnittsammlung verschiedene Fotos, die mich spontan «finden», schneide sie nach Gefühl zurecht, komponiere damit mein momentanes Innenbild, ergänze, wo nötig, klebe alles zusammen und produziere im S/W-Fotokopierer eine kleine Auflage.

Mit meinen Fähigkeiten als Zeichner und Maler, in Kombination mit Ängsten, Ungewissheiten, Schmerzen und diversen körperlichen Einschränkungen, gestalte ich im Format A4 aktuelle Bestandesaufnahmen, die ich dann in kleiner Auflage ausdrucke.

Erstaunlich, was man im Rollstuhl mit leichter Feinmotorikstörung auf einem weissen A4Papier, mit einer grossen Schachtel Zeitungsbilder, Schneidemesser, Leim, Pinzette, Geduld und Gestaltungswillen schliesslich im S/W-Kopierer drucken kann.
Der Künstler Jupe Haegler $\left({ }^{*} 1940\right)$ hat in etwa 250 Collagen aufgezeigt, wie er die Diagnose MS und deren Folgen erlebt und verarbeitet hat.

Die Schriftstellerin Jacqueline Crevoisier hat in Textform interpretiert, wie und was für sie daraus erkennbar wird. Die langjährige Zusammenarbeit der beiden hat eine neue Sichtform geschaffen, die Bild-Wort-Assemblage.

Eine Ausstellung dazu und ein Buch sind in Vorbereitung.
Korrespondenz: Jupe Haegler Hardturmstrasse 120 CH-8005 Zürich Tel. 0444407075 


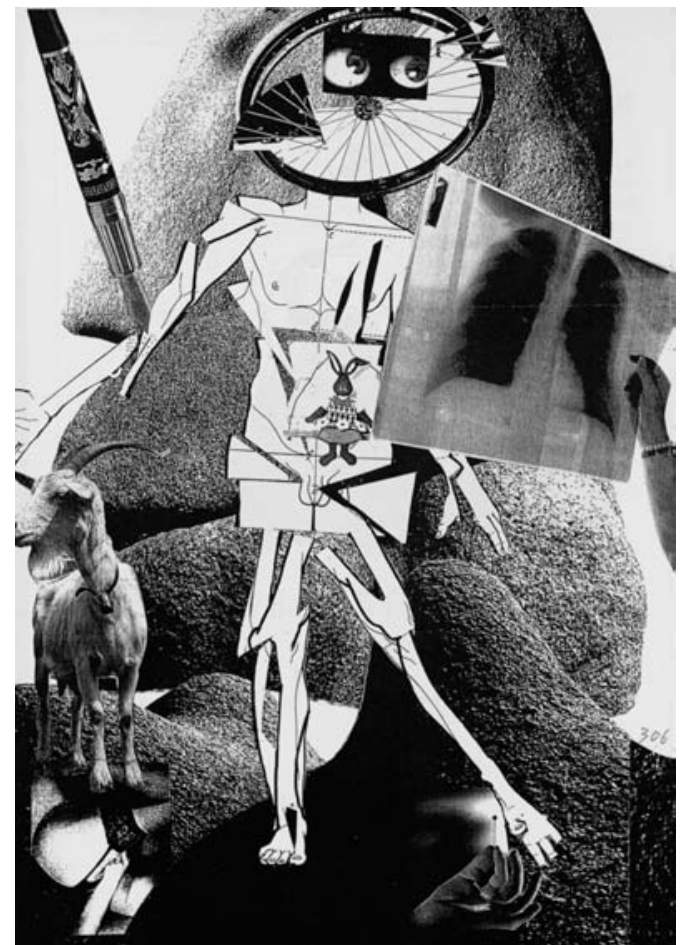

Die Sonne ging auf

und besänftigte die Weide:

«Vertrau mir. Ich würde dich nie so wie ein Blitz verkrüppeln.»

Die Sonne ging auf

und stach ihre Strahlen in die Augen eines Lichtempfindlichen:

«Freu dich. Ich vertreibe jeden Schatten von deiner Netzhaut.»

Die Sonne ging auf

und versengte das Oberteil der Braut:

«Schön ist sie. Deine Narbenbrust kann sich sehen lassen.»

Die Sonne ging auf

und nickte dem Verurteilten am Galgen Mut zu: «Durchhalten. Es wird schon werden.»

Die Sonne ging auf

und raste mit ihren Strahlenrad über Mensch und Erde:

«Geduld. Die nächste Sintflut kommt bestimmt.»

DIE SONNE GING AUF

Immer wieder -
Mit Nasenblut ins Logbuch des Wanderers eingetragen:

die Alpenpfade mit Nagelschuhen durchtrampelt Segmente in die Aussicht gestaunt die Geröllhalde hochgeklettert Berghütte entdeckt

Stecknadel im Heuhaufen gefunden Strapse der Sennerin gelöst

Geläut von Geissenglocken für Angelusläuten gehalten

mit Röntgenblick in mich geschaut: Osterhäsin gefunden.

Das Wandern ist DES MÜLLERS LUST. Seine schon.

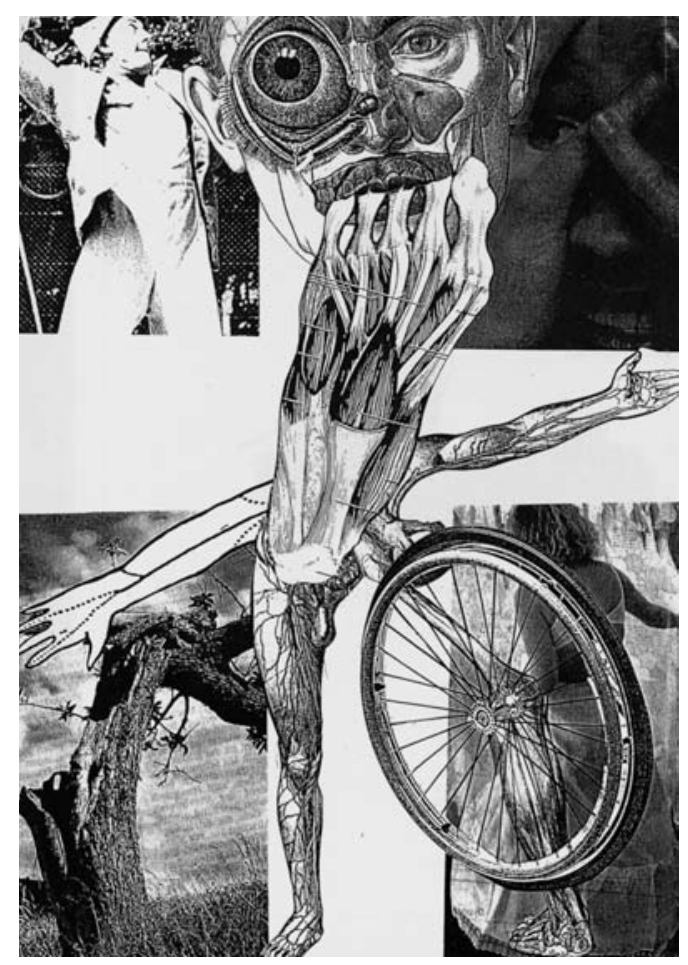

